\title{
Dynamic Effects of Diabatization in Distillation Columns
}

\section{Bisgaard, Thomas; Huusom, Jakob Kjøbsted; Abildskov, Jens}

\section{Published in:}

Proceedings of the 10th European Workshop on Advanced Control and Diagnosis

Publication date:

2012

Link back to DTU Orbit

Citation (APA):

Bisgaard, T., Huusom, J. K., \& Abildskov, J. (2012). Dynamic Effects of Diabatization in Distillation Columns. In Proceedings of the 10th European Workshop on Advanced Control and Diagnosis

\section{General rights}

Copyright and moral rights for the publications made accessible in the public portal are retained by the authors and/or other copyright owners and it is a condition of accessing publications that users recognise and abide by the legal requirements associated with these rights.

- Users may download and print one copy of any publication from the public portal for the purpose of private study or research.

- You may not further distribute the material or use it for any profit-making activity or commercial gain

- You may freely distribute the URL identifying the publication in the public portal

If you believe that this document breaches copyright please contact us providing details, and we will remove access to the work immediately and investigate your claim 


\title{
Dynamic Effects of Diabatization in Distillation Columns
}

\author{
Thomas Bisgaard* Jakob Kjøbsted Huusom* \\ Jens Abildskov* \\ * CAPEC, Dept. of Chemical and Biochemical Engineering, \\ Technical University of Denmark, Søltofts Plads, Bld. 229, \\ DK-2800 Kgs. Lyngby, Denmark
}

\begin{abstract}
The dynamic effects of diabatization in distillation columns are investigated in simulation with primary focus on the heat-integrated distillation column (HIDiC). A generic, dynamic, first-principle model has been formulated, which is flexible to describe various diabatic distillation configurations. Dynamic Relative Gain Array and Singular Value Analysis have been applied in a comparative study of a conventional distillation column and a HIDiC. The study showed increased input-output coupling due to diabatization. Feasible SISO control structures for the HIDiC were also found. Control-loop feasibility was demonstrated.
\end{abstract}

Keywords: Fluid separations, Distillation columns, Diabatic distillation, Dynamic modeling

\section{INTRODUCTION}

Multi-stage distillation is the most widely used industrial technique for continuously separating liquid mixtures. At the same time it is an energy intensive operation, so the technology still receives attention due to increased focus on environmental issues and resource management. In conventional distillation columns ( $\mathrm{CDiC})$ heat is added at the highest temperature and heat is removed at the lowest temperature, thereby preventing integration of the utility streams from the condenser and reboiler (Jana, 2010). Exergy (available energy) is thus said to be degraded throughout the distillation column. A Second-Law analysis (Fitzmorris and Mah, 1980) can quantify this exergy degradation. Such analysis reveals that industrial distillation columns operate at Second-Law efficiencies in the range of 5-20\% (de Koeijer and Kjelstrup, 2000). These low Second-Law efficiencies indicate a substantial potential for improvements.

Various alternative distillation column configurations with higher Second-Law efficiencies have been suggested. One group of alternative configurations are the diabatic distillation columns. In a diabatic distillation column the heat required to perform the separation is added and/or removed throughout the column. An example is the heatintegrated distillation column (HIDiC) which was conceptually introduced by Mah et al. (1977). An illustration of a $\mathrm{CDiC}$ and a general HIDiC is given in Figure 1.

Internal heat transfer in the HIDiC is realized by operating the rectifying section at higher pressure than the stripping section, using vapor recompression. This heat transfer facilitates gradual boil-up throughout the stripper and condensation throughout the rectifier leading to an improved Second-Law efficiency (Nakaiwa et al., 1998a). The HIDiC uses significantly less utility in form of steam and cooling water compared to the CDiC. Instead, energy

\footnotetext{
* E-mails: T. Bisgaard (thbis@kt.dtu.dk), J.K. Huusom
} (jkh@kt.dtu.dk), and J. Abildskov (ja@kt.dtu.dk) needs to be supplied to the compressor. Olujic et al. (2003) has shown that this operation significantly reduces the operation cost of the separation.

Extensive efforts have been made to develop this technology during the past 15 years, both theoretically (e.g. Nakaiwa et al. (2003); Gadalla et al. (2007); Jana (2010)) and experimentally (Naito et al., 2000; Brunisma et al., 2012). Despite demonstrations of large energy savings of the HIDiC compared to the CDiC and manageable operability, it has not yet been accepted by the industry. This could be due to lack of mature methods for designing these more complex configurations (Olujic et al., 2006; Gadalla et al., 2007; Suphanit, 2010). Furthermore operation is more complex as a result of the high degree of process integration (Nakaiwa et al., 1998b; Zhu and Liu, 2005b).

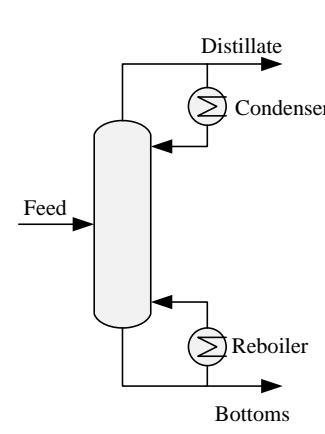

(a)

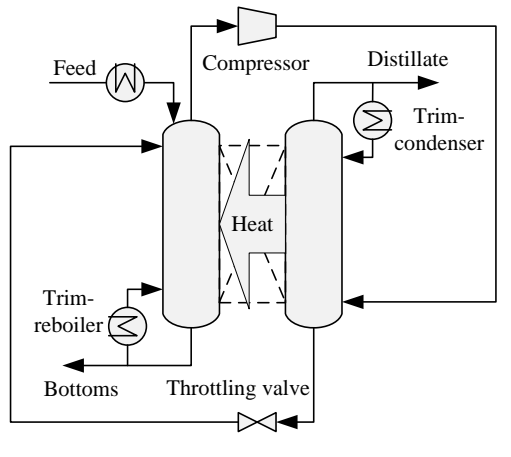

(b)
Fig. 1. Schematic representation of (a) conventional distillation column (CDiC), (b) general heat-integrated distillation column (HIDiC)

The scope of this study is to investigate the challenges related to process control which may arise from diabatization. We present a generic model for simulating operation of both the $\mathrm{CDiC}$ and $\mathrm{HIDiC}$ configurations. A SISO control structure selection is based on dynamic analysis 
tools and is verified in closed-loop simulations. The paper is organized with a presentation of the model in section 2 . The simulation case is defined and the results presented in section 3 before the concluding remarks in section 4 . Section 5 contains the nomenclature list.

\section{DISTILLATION COLUMN MODEL}

The modeling in this section forms the basis of the subsequent simulations presented in this paper. We give a detailed description of the distillation column configurations considered in this paper and their mathematical form, i.e. the dynamic model.

\subsection{System Description}

A distillation column consists of a rectifying section which contains the trays above the feed location and a stripping section which contains the feed tray and the trays below. In the rectifying section, the most volatile component is concentrated towards the top of the column. In the stripping section, the most volatile component is stripped off the down-flowing liquid, producing a bottom product rich in the least volatile component. A fraction of the condensed top product is returned to the column as a reflux while a fraction of the bottom product is vaporized and returned in the bottom of the column. By manipulating the amount of reflux and boilup, the purities of the top and bottom products can be adjusted. In a conventional (adiabatic) distillation column the column itself is thermally insulated from the surroundings. A diabatic distillation column on the other hand, exchanges heat with the surroundings on each tray. This can significantly reduce the need for condenser and reboiler duties. Figure 2 displays a general representation of a distillation column.

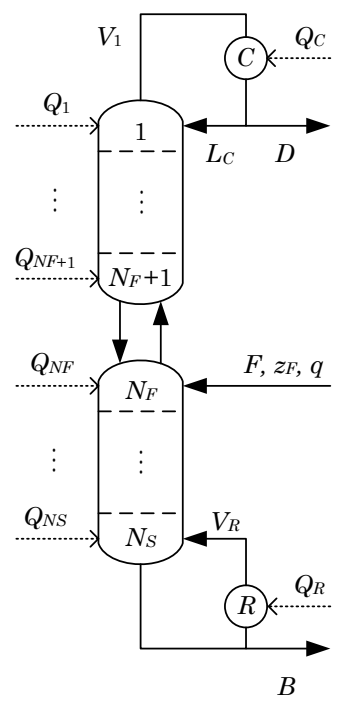

Fig. 2. General representation of a distillation column for separation of binary mixtures. The nomenclature is given in section 5

\subsection{Dynamic Model}

Inspired by the works of Liu and Qian (2000), Skogestad and Morari (1988), and Skogestad (1997) a dynamic model is formulated to describe both an adiabatic and a diabatic distillation column. The dynamic model includes mass and energy balances with the following assumptions:

(1) A Lewis/Randall ideal, binary mixture is considered

(2) A tray column model is used

(3) Ideal mixing and equilibrium on each tray

(4) Changes in sensible heat have been neglected

(5) An equal number of trays in the rectifying and stripping sections

(6) Vapor holdup is neglected corresponding to constant pressure in the $\mathrm{CDiC}$ and constant pressures in the rectifying and stripping sections in the HIDiC

(7) Liquid flows are described by linearized tray hydraulics

The model equations are summarized in Table 1 and the corresponding nomenclature list is given in section 5. As can be seen, the expression for the $Q_{i}$ terms determine the configuration of the distillation column.

\subsection{Control Degrees of Freedom Analysis}

A crucial element in the operation of a distillation column is the selection of an efficient control structure, i.e. the pairing of controlled and manipulated variables. Control degrees of freedom analysis were performed on a $\mathrm{CDiC}$ and a HIDiC. A CDiC has five control degrees of freedom, namely the condenser duty, the reboiler duty, the distillate flow rate, the bottom flow rate and the reflux flow rate. Three holdups must be controlled, which are the reflux drum holdup, the reboiler holdup and the column vapor holdup, leaving the two product purities left for control. When considering the general HIDiC configuration as illustrated in Figure 1, two additional control degrees of freedom exist. These are the pressure difference between the rectifying and stripping sections and the feed preheater duty. As a result, the complexity of the control structure synthesis problem has increased, thanks to diabatization since the number of combinations have increased.

\section{SIMULATION STUDY}

The model described in section 2 has been implemented in MATLAB ${ }^{\circledR}$. This section outlines the considered case study, the methods applied for analysis, and finally the results and a discussion of these. A binary, equimolar mixture of benzene-toluene is a common example mixture (Zhu and Liu, 2005a; Huang et al., 2007) and is used in this work as well.

\subsection{Case-formulation}

The idea is to compare the dynamics of an adiabatic distillation column (the $\mathrm{CDiC}$ ) with a diabatic distillation column (the HIDiC), so the design degrees of freedom must be chosen according to this. The specific HIDiC configuration, presented in this paper, is the configuration as seen in Figure 1(b) without a feed preheater. The feed stream for the two configurations must obviously be the same, i.e. the feed flow rate, composition and thermal condition. The stripping section pressure of both configurations are fixed at $0.1013 \mathrm{MPa}$. The pressure of the rectifying section of the $\mathrm{CDiC}$ is identical to the pressure in the stripping section 
while the pressure difference between the rectifying and stripping sections of the HIDiC is specified as $0.217 \mathrm{MPa}$. Additionally the product specifications are $99 \%$ benzene in the distillate and $5 \%$ benzene in the bottom product. It was furthermore decided that the $\mathrm{CDiC}$ and HIDiC should be designed with equal number of trays such that the hydraulic lag in the column, i.e. the time a change in the liquid flow in the top is perturbed to the bottom, is unaffected by the configuration type. A complete list of all specifications related to column design and mixture properties are given in Table 2 .

Table 2. Stationary operation data and model parameters for numerical studies related to the separation of a binary mixture of benzenetoluene

\begin{tabular}{|c|c|c|}
\hline \multicolumn{3}{|l|}{ General operation conditions } \\
\hline Number of stages & 20 & - \\
\hline Feed stage location & 11 & - \\
\hline Feed flow & 100 & $\mathrm{kmol} \cdot \mathrm{h}^{-1}$ \\
\hline Feed benzene content & 0.50 & - \\
\hline Feed thermal condition & 1 & - \\
\hline Stripping section pressure & 0.1013 & $\mathrm{MPa}$ \\
\hline Top purity & 0.99 & - \\
\hline Bottom purity & 0.95 & - \\
\hline Nominal tray holdup & 0.83 & kmol \\
\hline \multicolumn{3}{|c|}{ CDiC specific operation conditions } \\
\hline Reflux flow rate & 86.6 & $\mathrm{kmol} \cdot \mathrm{h}^{-1}$ \\
\hline Vapor boilup rate & 134 & $\mathrm{kmol} \cdot \mathrm{h}^{-1}$ \\
\hline Pressure diff. between sections & 0 & $\mathrm{MPa}$ \\
\hline \multicolumn{3}{|c|}{ HIDiC specific operation conditions } \\
\hline Reflux flow rate & 23.9 & $\mathrm{kmol} \cdot \mathrm{h}^{-1}$ \\
\hline Vapor boilup rate & 71.8 & $\mathrm{kmol} \cdot \mathrm{h}^{-1}$ \\
\hline Pressure diff. between sections & 0.217 & $\mathrm{MPa}$ \\
\hline \multicolumn{3}{|l|}{ Model parameters } \\
\hline Hydraulic time constant & 0.0042 & $\mathrm{~h}$ \\
\hline Heat of vaporization & 30001.1 & $\mathrm{~kJ} \cdot \mathrm{kmol}^{-1}$ \\
\hline Relative volatility & 2.317 & - \\
\hline Heat transfer rate & 9803 & $\mathrm{~kJ} \cdot \mathrm{h}^{-1} \cdot \mathrm{K}^{-1}$ \\
\hline Antoine parameters for & 15.9008 & - \\
\hline \multirow[t]{2}{*}{ benzene (in Torr and K) } & 2788.51 & - \\
\hline & -52.36 & - \\
\hline
\end{tabular}

\subsection{Dynamic Controllability Analysis}

The control structure synthesis problem for dual composition control for a CDiC is usually solved by considering a decentralized $2 \times 2$ control problem (Skogestad et al., 1990). This procedure has been employed in this study as well, implying perfect control for the remaining loops not concerning compositions.

Three potential manipulated variables are considered in the studies of controllability for the top composition, namely the reflux flow $L$, the distillate flow $D$ or the reflux ratio $L / D$. Three potential manipulated variables are considered for the bottom purity as well, namely the boilup $V$, bottom flow $B$ and the boilup ratio $V / B$. If all combinations are considered this leaves nine possible combinations for pairing. In order to assess the various control structures, the dynamic Bristol's Relative Gain Array method (RGA) and Singular Value Analysis (SVA) have been employed. Both methods are based on linear models and are described by e.g. Skogestad and Postlethwaite (1996). For this purpose the full order model has been linearized at the stationary operation point, and represented as a transfer function model:

$$
\mathbf{y}(s)=\mathbf{G}(s) \mathbf{u}(s)
$$

Where $\mathbf{G}(s)$ is the process transfer function matrix in the Laplace domain, linking the inputs, $\mathbf{u}(s)$, to the outputs, $\mathbf{y}(s)=\left(Y_{D}, X_{B}\right)^{T}$. Logarithmic compositions, $Y_{D}$ and $X_{B}$, for the outputs have been applied as suggested by Skogestad and Morari (1988):

$$
\begin{aligned}
& Y_{D}=\ln \left(1-y_{D}\right) \\
& X_{B}=\ln x_{B}
\end{aligned}
$$

Based on this transfer function matrix the frequency dependent RGA is given by:

$$
\mathbf{\Lambda}(j \omega)=\mathbf{G}(j \omega) \otimes\left[\mathbf{G}(j \omega)^{-1}\right]^{T}
$$

The diagonal elements in a $2 \times 2$ RGA, $\boldsymbol{\Lambda}$, are identical and will be referred to as $\lambda$. The operator " $\otimes$ " is the Schur product, i.e. the element-wise multiplication operator.

In SVA the process transfer function matrix is decomposed to orthonormal matrices, $\mathbf{Z}$ and $\mathbf{V}$, and a diagonal matrix $\mathbf{S}$, according to:

$$
\mathbf{G}(s)=\mathbf{Z}(s) \mathbf{S}(s) \mathbf{V}(s)^{T}
$$

The condition number of the process transfer function matrix is given by the ratio between the largest and the smallest, non-zero diagonal element (or singular value) in S:

$$
\gamma(j \omega)=\frac{\sigma^{*}(j \omega)}{\sigma_{*}(j \omega)}
$$

When applying SVA, scaling of input and output variables must be applied. For this purpose the flow input variables are scaled with the valve gain equal to twice the magnitudes of the nominal values while ratios are simply scaled by their nominal values.

The magnitude of the relative gain element, $\lambda$, relates to the degree of interaction between the inputs and outputs. The desired value of the relative gain element is unity. This corresponds to the case where two single loops can be designed independently since no loop interaction exists. The condition number quantifies the sensitivity of the system to uncertainties in the matrix. Physically this means that the gain of the plant depends strongly on the input direction. A high condition number indicates poor conditioning of the process matrix, thus a high condition number indicate that a process is difficult to control. A value of 10 and above is typically considered as the highend condition number of the process matrix. The frequency range of importance for feedback control in a distillation column, is the range of $0.01-1 \mathrm{~min}^{-1}$ corresponding to 0.6 $60 \mathrm{~h}^{-1}$ (Skogestad et al., 1990).

\subsection{Results and Discussion}

This section provides a comparison between a HIDiC and a CDiC. The steady-state RGA elements and condition numbers for the CDiC and the HIDiC are listed in Table 3 with the given control structures. The dynamic RGA 
elements and condition numbers are illustrated in Figure 3 . When considering the steady-state values in Table 3 the condition number varies significantly between the control structures. It is clear that the $L B$ - and $(L / D)(V / B)$ structures are the best candidates for both distillation column configurations. No information is available for the $D B$-structure due to open-loop instability. Typically this steady-state analysis does not provide the complete picture since e.g. $D B$ is a feasible structure when the loop is closed. When it comes to the dynamic analysis it can be seen in Figure 3 that the HIDiC has a greater degree of interaction than its conventional counterpart, since roughly all the lines representing the $\mathrm{HIDiC}$ have moved further away from unity compared to the lines belonging to the CDiC. Note the RGA element converges to unity (i.e. completely uncoupled system) at high frequencies since a hydraulic lag exist within the column. An interesting observation is the significant influence on the control structures involving ratios, $L(V / B),(L / D) V$ and $(L / D)(V / B)$ control structures in particular, whose coupling have increased compared to the CDiC. This is expected since composition changes causes changes in the vapor and liquid flows within the column. It seems that the $L B$-structure is still superior for both configurations.

The performance of the $L B$-structure has been evaluated using closed-loop simulation for a feedback SISOcontroller. For this evaluation, a PI-controller was incorporated in the model in discrete time with a sampling time of $0.0833 \mathrm{~h}$. The controller uses the reflux flow rate to control the top purity (loop $d Y_{D}-d L$ ) and the bottom product flow rate to control the bottom purity (loop $\left.d X_{B}-d B\right)$. Again, logarithmic compositions have been used for controlled and measured variables. The dynamic responses of a $+10 \%$ step-change in feed flow rate and a $-10 \%$ step-change in feed composition is given in Figure 4. The simulations reveal a satisfactory control performance to the relative large step-changes.
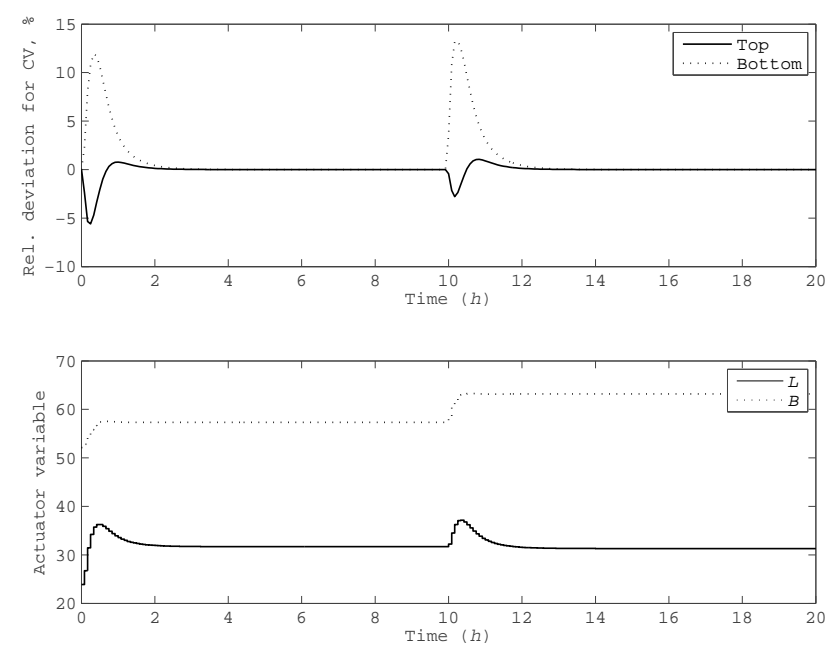

Fig. 4. Closed-loop response for the HIDiC to a $+10 \%$ stepchange in feed flow rate at time $t=0 \mathrm{~h}$ and a $-10 \%$ step-change in feed composition at $t=15 \mathrm{~h}$. Tuning parameters: $d Y_{D}-d L, K_{c}=-0.0790, \tau_{I}=0.5158 \mathrm{~h}$ and $d X_{B}-d B, K_{c}=8.3147, \tau_{I}=0.4357 \mathrm{~h}$.

\section{CONCLUDING REMARKS}

In this paper, a complete dynamic model has been presented and utilized for dynamic analysis and simulation of a heat-integrated distillation column (HIDiC) and a conventional distillation column. Dynamic analysis showed an increased input-output coupling due to diabatization, and that otherwise feasible control structures for a conventional distillation column could turn infeasible in a HIDiC. In this study an $L B$-structure seemed to be a promising control structure for a $\mathrm{HIDiC}$ as well as a conventional distillation column, considering a case-study of a benzenetoluene separation with $99 \%$ benzene in the distillate and $5 \%$ in the bottom product.

\section{NOMENCLATURE}

\begin{tabular}{|c|c|c|}
\hline \multicolumn{3}{|c|}{ Symbols } \\
\hline$B$ & $\mathrm{kmol} \cdot \mathrm{h}^{-1}$ & Bottom flow \\
\hline$c$ & - & Benzene Antoine parameters \\
\hline$D$ & $\mathrm{kmol} \cdot \mathrm{h}^{-1}$ & Distillate flow \\
\hline$F$ & $\mathrm{kmol} \cdot \mathrm{h}^{-1}$ & Feed flow \\
\hline G & - & Process transfer function matrix \\
\hline$j$ & - & Imaginary number \\
\hline$L$ & $\mathrm{kmol} \cdot \mathrm{h}^{-1}$ & Liquid flow \\
\hline$M$ & $\mathrm{kmol}$ & Holdup \\
\hline$N$ & - & Number \\
\hline$P$ & $\mathrm{MPa}$ & Pressure \\
\hline$q$ & - & Feed thermal condition \\
\hline$Q$ & $\mathrm{~kJ} \cdot \mathrm{h}^{-1}$ & Stage heat transfer \\
\hline$T$ & $\mathrm{~K}$ & Temperature \\
\hline$U A$ & $\mathrm{~kJ} \cdot \mathrm{h}^{-1} \cdot \mathrm{K}^{-1}$ & Heat transfer rate \\
\hline $\mathbf{u}$ & - & Model input matrix \\
\hline $\mathbf{U}$ & - & Orthonormal basis in SVA \\
\hline$V$ & $\mathrm{kmol} \cdot \mathrm{h}^{-1}$ & Vapor flow \\
\hline$x$ & - & Liquid light component mole fraction \\
\hline$X$ & - & Logarithmic mole fraction \\
\hline$y$ & - & Vapor light component mole fraction \\
\hline$Y$ & - & Logarithmic mole fraction \\
\hline $\mathbf{y}$ & - & Model output matrix \\
\hline$z$ & - & Feed light component mole fraction \\
\hline $\mathbf{Z}$ & - & Orthonormal basis in SVA \\
\hline$\alpha$ & - & Relative volatility \\
\hline$\gamma$ & - & Condition number \\
\hline$\lambda$ & $\mathrm{kJ} \cdot \mathrm{kmol}^{-1}$ & Heat transfer rate \\
\hline$\lambda$ & - & RGA diagonal element \\
\hline$\Lambda$ & - & RGA \\
\hline$\tau$ & $\mathrm{h}$ & Hydraulic time constant \\
\hline$\sigma$ & - & Singular value \\
\hline$\omega$ & $\mathrm{h}^{-1}$ & Frequency \\
\hline
\end{tabular}

Super- and subscripts

$B \quad$ Bottom

C Condenser

$D \quad$ Distillate

$F \quad$ Feed

$i \quad$ Stage number

$R \quad$ Reboiler

$s \quad$ Nominal operation condition

$S \quad$ Stage

\section{Acronyms}

CDiC Conventional distillation column

HIDiC Heat-integrated distillation column

RGA Relative gain array

SVA Singular value analysis 

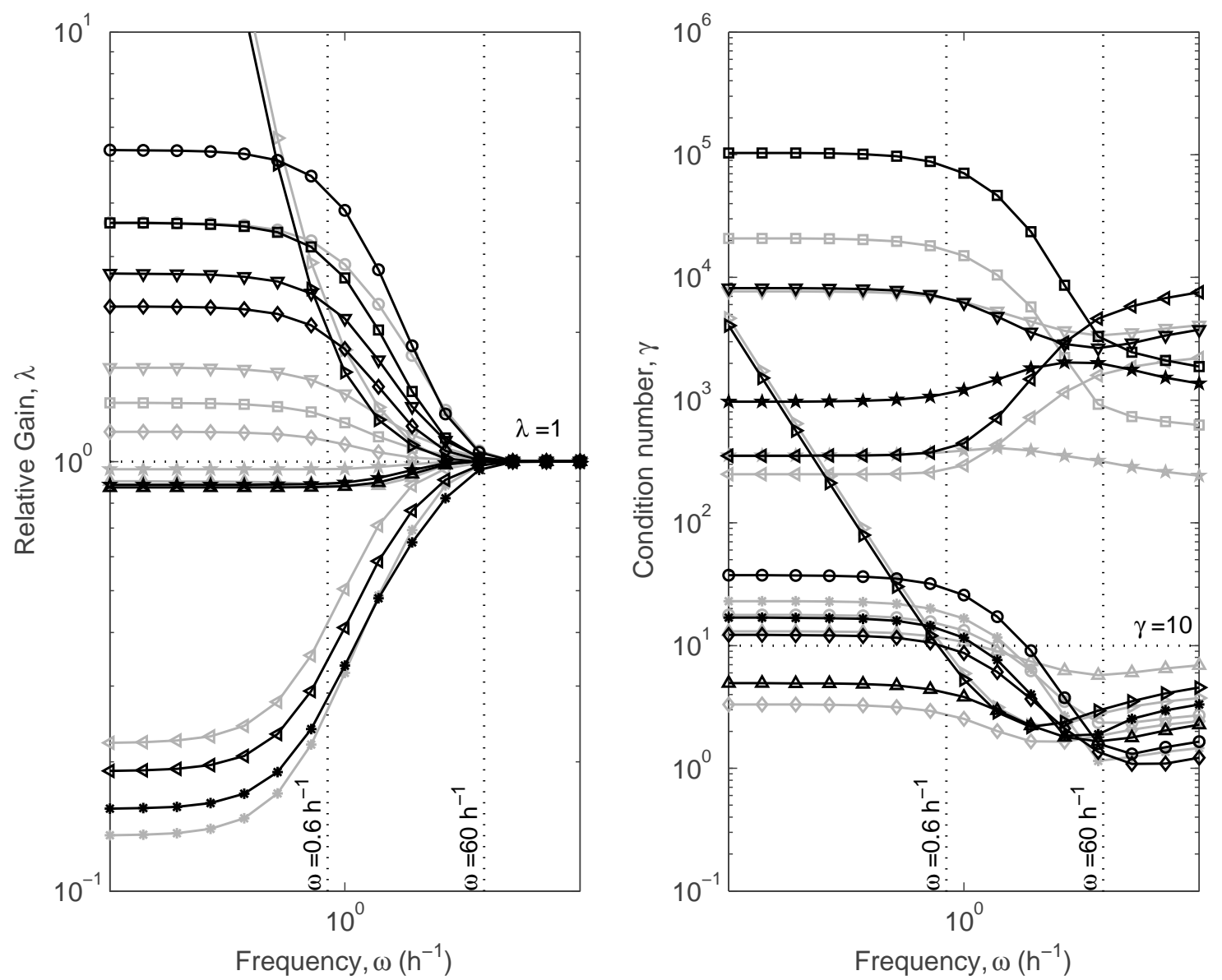

Fig. 3. Dynamic RGA Analysis and SVA applied on a HIDiC (black lines) and a CDiC (gray lines). The pressure difference between sections in the HIDiC is kept constant. Legends: Dotted: Lines of interest. (०): $L V$. (*): $D V$. $(\square):(L / D) V .(\triangle): L B \cdot(\nabla): L(V / B) .(\triangleright): D B .(\triangleleft): D(V / B) .(\star):(L / D) B .(\diamond):(L / D)(V / B)$.

\section{REFERENCES}

Brunisma, O., Krikken, T., Cot, J., Saric, M., Tromp, S., Olujic, Z., and Stankiewicz, A. (2012). The structured heat integrated distillation column. Chem. Eng. Res. Des., 90, 458-470.

Fitzmorris, R. and Mah, R. (1980). Improving distillation column design using thermodynamic availability analysis. AIChE Journal, 26, 265-273.

Gadalla, M., Jimenz, L., Olujic, Z., and Jansens, P. (2007). A thermo-hydraulic approach to conceptual design of an internally heat-integrated distillation column (i-hidic). Comput. Chem. Eng., 31, 1346-1354.

Huang, K., Wang, S., Iwakabe, K., Shan, L., and Zhu, Q. (2007). Temperature control of an ideal heat-integrated distillation column (hidic). Chem. Eng. Sci., 62, 64866491.

Jana, A. (2010). Heat integrated distillation operation. Appl. Energy, 87, 1477-1494.

Liu, X. and Qian, J. (2000). Modeling, control, and optimization of ideal internal thermally coupled distillation columns. Chem. Eng. Technol., 23, 235-241.

Mah, R., J.J. Nicholas, J., and Wodnik, R. (1977). Distillation with secondary reflux and vaporization: A comparative evaluation. AIChE Journal, 23, 651-658.

Naito, K., Nakaiwa, M., Huang, K., Endo, A., Aso, K., Nakanishi, T., Nakamura, T., Noda, H., and Takamatsu,
T. (2000). Operation of a bench-scale ideal heat integrated distillation column (hidic): an experimental study. Comput. Chem. Eng., 24, 495-499.

Nakaiwa, M., Huang, K., Endo, A., Ohmori, T., Akiya, T., and Takamatsu, T. (2003). Internally heat-integrated distillation columns: a review. Trans IChemE, 81, 162177.

Nakaiwa, M., Huang, K., Owa, M., Akiya, T., Nakane, T., Sato, M., Takamatsu, T., and Yoshitome, H. (1998a). Potential energy savings in ideal heat-integrate distillation column. Appl. Therm. Eng., 18, 1077-1087.

Nakaiwa, M., Huang, K., Owa, M., Akiya, T., Nakane, T., and Takamatsu, T. (1998b). Operating an ideal heat integrated distillation column with different control algorithms. Comput. Chem. Eng., 22, 389-393.

Olujic, Z., Fakhri, F., de Rijke, A., de Graauw, J., and Jansen, P. (2003). Internal heat integration - the key to an energy-conserving distillation column. J. Chem. Technol. Biotechnol., 78, 241-248.

Olujic, Z., Sun, L., Rijke, A.D., and Jansens, P. (2006). Conceptual design of an internally heat integrated propylene-propane splitter. Energy, 31, 3083-3096.

Skogestad, S. (1997). Dynamics and control of distillation columns - a critical survey. Modeling, Identification and Control, 18, 177-217. 
Skogestad, S., Lundström, P., and Jacobsen, E. (1990). Selecting the best distillation control configuration. AIChE Journal, 36, 753-764.

Skogestad, S. and Morari, M. (1988). Understanding the dynamic behavior of distillation columns. Ind. Eng. Chem. Res., 27, 1848-1862.

Skogestad, S. and Postlethwaite, I. (1996). Multivariable feedback control: Analysis and design. Wiley.

Suphanit, B. (2010). Design of internally heat-integrated distillation column (hidic): Uniform heat transfer area versus uniform heat distribution. Energy, 35, 1505-1514.

de Koeijer, G. and Kjelstrup, S. (2000). Minimizing entropy production rate in binary tray distillation. Int. J. Applied Thermodynamics, 3, 105-110.

Zhu, Y. and Liu, X. (2005a). Dynamics and control of high purity heat integrated distillation column. Ind. Eng. Chem. Res., 44, 8806-8814.

Zhu, Y. and Liu, X. (2005b). Investigating control schemes for an ideal thermally coupled distillation column (itcdic). Chem. Eng. Technol., 28, 1048-1055. 
Table 1. Equations for a dynamic model being capable of describing the CDiC and the HIDiC configurations. The tray number, $i$, in the distillation column is counted from top to bottom. A corresponding nomenclature list is given in section 5 . The operator $:=$ should be considered as a dynamic equal sign

\begin{tabular}{|c|c|c|}
\hline Provide & $N_{S}, F, z_{F}, q, P_{i}, \alpha, L_{C}, V_{R}, C 1, C 2, C 3, \lambda, U A$ and initial conditions & \\
\hline Variable & Expression & Stages \\
\hline Feed stage & $N_{F}=N_{S} / 2+1$ & \\
\hline Vapor pressure & $P_{i}^{*}=\frac{P_{i}}{x_{i}+\left(1-x_{i}\right) / \alpha}$ & $i=1, \ldots, N_{S}$ \\
\hline Temperature & $T_{i}=\frac{c_{2}}{c_{1}-\ln P_{i}^{*}}-C_{3}$ & $i=1, \ldots, N_{S}$ \\
\hline VLE & $y_{i}=\frac{\alpha x_{i}}{(\alpha-1) x_{i}+1}$ & $i=1, \ldots, N_{S}$ \\
\hline \multirow[t]{2}{*}{ Heat transfer } & $\begin{array}{l}\text { CDiC: } \\
Q_{i}=0\end{array}$ & $i=1, \ldots, N_{S}$ \\
\hline & $\begin{array}{l}\text { HIDiC: } \\
Q_{i}=-Q_{N_{F}-1+i}=U A\left(T_{N_{F}-1+i}-T_{i}\right)\end{array}$ & $i=1, \ldots, N_{F}-1$ \\
\hline Vapor flow & $\begin{aligned} V_{i} & =V_{R}+\sum_{k=i}^{N_{S}} Q_{k} / \lambda \\
V_{i} & :=V_{i}+F(q-1)\end{aligned}$ & $\begin{array}{l}i=1, \ldots, N_{S} \\
i=N_{F}, \ldots, N_{S}\end{array}$ \\
\hline \multirow{2}{*}{ Liquid flow } & $\begin{array}{l}L_{i}=L_{s, i}+\left(M_{i}-M_{s, i}\right) / \tau \\
\text { Where }\end{array}$ & $i=1, \ldots, N_{S}$ \\
\hline & $\begin{array}{l}L_{s, i}=L_{C, s}-\sum_{k=1}^{i} Q_{k} / \lambda \\
L_{s, i}:=L_{s, i}+F q \\
\mathrm{HIDiC}: \\
L_{N_{F}-1}=V_{N_{F}}+L_{N_{F}-2}-V_{N_{F}-1}\end{array}$ & $\begin{array}{l}i=1, \ldots, N_{S} \\
i=N_{F}, \ldots, N_{S}\end{array}$ \\
\hline Total holdups & $\begin{array}{l}d M_{1} / d t=V_{2}+L_{C}-V_{1}-L_{1} \\
d M_{i} / d t=V_{i+1}+L_{i-1}-V_{i}-L_{i} \\
d M_{N_{S}} / d t=V_{R}+L_{N_{S}-1}-V_{N_{S}}-L_{i} \\
d M_{N_{F}} / d t:=d M_{N_{F}} / d t+F\end{array}$ & $\begin{aligned} i & =1 \\
i & =2, \ldots, N_{S}-1 \\
i & =N_{S} \\
i & =N_{F}\end{aligned}$ \\
\hline Component holdup & $\begin{array}{l}d x_{1} / d t=\left(V_{2} y_{2}+L_{C} x_{C}-V_{1} y_{1}-L_{1} x_{i}-x_{1} d M_{1} / d t\right) / M_{1} \\
d x_{i} / d t=\left(V_{i+1} y_{i+1}+L_{i-1} x_{i-1}-V_{i} y_{i}-L_{i} x_{i}-x_{i} d M_{i} / d t\right) / M_{i} \\
d x_{N_{S}} / d t=\left(V_{R} y_{R}+L_{N_{S}-1} x_{N_{S}-1}-V_{N_{S}} y_{N_{S}}-L_{i} x_{N_{S}}-x_{N_{S}} d M_{N_{S}} / d t\right) / M_{N_{S}} \\
d x_{N_{F}} / d t:=d x_{N_{F}} / d t+F\left(z_{F}-x_{N_{F}}\right) / M_{N_{F}}\end{array}$ & $\begin{aligned} i & =1 \\
i & =2, \ldots, N_{S} \\
i & =N_{S} \\
i & =N_{F}\end{aligned}$ \\
\hline Condenser & $\begin{array}{l}d x_{C} / d t=\left(V_{1} y_{1}-L_{C} x_{C}-D x_{D}\right) / M_{C} \\
\text { Total: } y_{D}=x_{C}=y_{1}\end{array}$ & \\
\hline Reboiler & $\begin{array}{l}d x_{R} / d t=\left(L_{N_{S}} x_{N_{S}}-V_{R} y_{R}-B x_{R}\right) / M_{R} \\
\text { Total: } x_{R}=y_{R}=x_{B}\end{array}$ & \\
\hline
\end{tabular}

Table 3. Stationary RGA elements and condition numbers for potential configurations of the $\mathrm{CDiC}$ and the HIDiC related to the separation of an equimolar benzene-toluene mixture

\begin{tabular}{l|ll|ll}
\hline & \multicolumn{3}{l}{ CDiC } & \\
Control structure & RGA element, $\lambda$ & Condition number, $\gamma$ & RGA element, $\lambda$ & Condition number, $\gamma$ \\
\hline$L V$ & 5.31 & 37.43 & 3.60 & 17.77 \\
$D V$ & 0.16 & 16.92 & 0.13 & 23.06 \\
$(L / D) V$ & 3.60 & 103575 & 1.37 & 20816 \\
$L B$ & 0.87 & 4.94 & 0.90 & 13.08 \\
$L(V / B)$ & 2.74 & 8188 & 1.65 & 7701 \\
$D B$ & $\infty$ & $\infty$ & $\infty$ & $\infty$ \\
$D(V / B)$ & 0.19 & 352 & 0.22 & 248 \\
$(L / D) B$ & 0.88 & 972 & 0.96 & 354 \\
$(L / D)(V / B)$ & 2.30 & 12.22 & 1.17 & 3.32 \\
\hline
\end{tabular}

